\title{
How do air pollution and meteorological parameters contribute to the spread of COVID-19 in Saudi Arabia?
}

\author{
Abderrazek Ben Maatoug ${ }^{1,2} \cdot$ Mohamed Bilel Triki $^{2,3}$ (D) $\cdot$ Hesham Fazel $^{4}$ \\ Received: 17 February 2021 / Accepted: 17 March 2021 / Published online: 12 April 2021 \\ (C) The Author(s), under exclusive licence to Springer-Verlag GmbH Germany, part of Springer Nature 2021
}

\begin{abstract}
The current global health crisis is unprecedented in modern times. It has killed numerous people, caused great suffering, and turned many people's lives upside down. This study seeks to investigate the role of some pollutants and the meteorological parameters in the transmission of the virus (SARS-CoV-2). The number of infections identified in Saudi Arabia, a country with a hot climate, was studied for a period between March 9, 2020 and November 19, 2020, which was characterized by a single wave with a peak of 4,919 cases on June 17,2020. Based on count data models, we observed that air pollution and meteorological parameters considerably influenced the daily evolution of infections in most affected cities of Saudi Arabia (Riyadh, Jeddah, and Makkah) where the prevalence of the disease was relatively high during summer 2020. Our study suggests that air pollution could be a significant risk factor for respiratory infections and virus transmission. On the other hand, meteorological factors and high concentration of air pollutants should be taken into account by public decision-makers in Saudi Arabia when seeking to limit COVID-19 transmission.
\end{abstract}

Keywords COVID-19 $\cdot$ Air pollution $\cdot$ GLM $\cdot$ Count data models

\section{Introduction}

On March 11, 2020, the World Health Organization (WHO) declared that the outbreak of a novel coronavirus had become a "global pandemic." Since then, COVID-19 has spread around the world, with large numbers of people becoming infected. There is now much talk about a second wave of this

Responsible Editor: Lotfi Aleya

Mohamed Bilel Triki

mtriki@ub.edu.sa

Abderrazek Ben Maatoug

abenmaatouk@ub.edu.sa

Hesham Fazel

hfazel@ub.edu.sa

1 Health Economics, Faculty of Business, University of Bisha, P.O. Box 551, Bisha 61922, Saudi Arabia

2 GEF2A Lab, University of Tunis, Tunis, Tunisia

3 Applied Statistics, Community College, University of Bisha, P.O. Box 551, Bisha 61922, Saudi Arabia

4 Health Marketing, Faculty of Business, University of Bisha, P.O. Box 551, Bisha 61922, Saudi Arabia pandemic hitting many countries. Due to its propensity to spread rapidly, COVID-19 presents risks for people's health and their economic and social wellbeing, such as by causing job losses and depriving people of social contact.

For Saudi Arabia, on November 19, there were 354,813 confirmed cases and 5,745 deaths reported, which corresponds to 10,619 and 172 per million, respectively. An initial overview of statistics relating to COVID-19 infections highlights the importance of the epidemic's extension over summer 2020, with there being a peak of 4,919 cases on June 17 . Many factors - such as social relationships, human connectivity, urbanization, the widespread use of air conditioning, and international travel - pose challenges for preventing and controlling COVID-19. In addition, epidemiological studies have concluded that environmental conditions can contribute to the spread of COVID-19 (Brassey et al. 2020).

Statistical models represent a valuable tool for understanding the channels through which the virus is transmitted, and this can inform public health decision-making. However, understanding the dynamics of coronavirus transmission remains a difficult task due to the spatial extension of the pandemic.

Since the start of the coronavirus pandemic, Saudi Arabia has mobilized to ensure the health of its citizens. The virus has 
continued to circulate, however, and it presents a danger for the entire population. It is therefore imperative to remain vigilant in the face of the COVID-19 pandemic and take into account any necessary measures to ensure health security while also maintaining and stimulating the economy.

Essential measures were taken to try to slow down the spread of COVID-19, which grew exponentially over the summer of 2020. These included closing public administrations, schools, and other public facilities. In addition, in March, the Saudi authorities suspended all international and domestic flights and established a curfew in major cities.

Concerning meteorological parameters, some authors have drawn a parallel between the new coronavirus and seasonal influenza, as well as the 2003 outbreak of SARS in Asia. The contribution that meteorological parameters make to the spread of the virus has been the subject of several studies (Chen et al. 2020; Gupta et al. 2020; Ma et al. 2020; Poole 2020; Sajadi et al. 2020; Wang et al. 2020). At present, the virus is circulating less than before in Saudi Arabia, but it is still there. A resurgence in COVID-19 cases is therefore possible if preventive measures begin to slip. The WHO issued several warnings to this effect, citing the possibility of a second wave in the autumn. This feared rebound is now affecting several countries that had succeeded in reducing cases over the summer, such as France, Spain, the UK, and many other European countries. There appears to be a close relationship between COVID-19 cases and climatic conditions (Yuan et al. 2006), and there is a causal relationship between climatic parameters and the biological interactions between humans and the SARA-CoV-2 virus.

In addition, the air quality in cities often affects the health of populations. In particular, tropospheric ozone (O3) and nitrogen oxide (NOx) tend to increase respiratory diseases such as asthma, chronic obstructive pulmonary disease and weakens the lungs by making them more prone to infections (Strak et al. 2017). Infection with coronavirus 2 is associated with Severe Acute Respiratory Syndrome (SARS-CoV-2), the virus that causes COVID-19, can cause severe damage to the airways, as well as fatal lung failure. It has been shown that there is a strong dependence between air pollution and COVID-19 (Conticini et al. 2020; Wu et al. 2020). In addition, Setti et al. (2020) showed the importance of airborne particles (PM) in the transmission of the virus. It turns out that the risk of infection is increased in cities with high population concentrations.

Since the 1980s, various authors have demonstrated a correlation between mortality rate and cases of pneumonia (Bull 1980). Climatic conditions - such as temperature, humidity, and wind speed - and air quality can contribute to the spread of some viruses (Dalziel et al. 2018; Brandt et al. 2020). Recently, Tosepu et al. (2020) showed that meteorological factors played a role in the spread of the COVID-19 pandemic in Jakarta. Several studies have highlighted a close association between air pollution and the severity of COVID-19 in the form of worsening respiratory or cardiovascular diseases (Conticini et al. 2020; Dutheil et al. 2020).

Kumar and Kumar (2020), meanwhile, analyzed the relationship between weather parameters and the COVID-19 pandemic in the Indian city of Mumbai. Based on a Spearman rank correlation test, they found evidence to suggest that temperature and relative humidity are related to cases of COVID19. These meteorological parameters were used to model and predict COVID-19 infections using an Artificial Neural Network.

Using the Canadian COVID-19 database as the basis, To et al. (2020) challenged the hypothesis that lower temperatures increase the transmission of COVID-19. Their multiple linear regression model revealed a positive but statistically insignificant effect of temperature on total COVID-19 cases. They put forward the high number of COVID-19 cases in countries with a warmer climate-such as India, Iran, and Brazil-as a possible cause of the effect of meteorological parameters on the spread of the pandemic.

Next, Oztig and Askin (2020) examined the relationship between human mobility and total COVID-19 cases in some countries. Through a negative binomial model, they showed that there was a positive significant effect of passenger flow on the total number of COVID-19 infections in 144 countries. Chan et al. (2021), meanwhile, proposed counting models for forecasting daily cases in 18 countries. Their results support the superiority of the negative binomial model for estimating the trend and spread of the epidemic, with them also suggesting that a count regression model is better suited for modeling new daily cases.

In the case of Saudi Arabia, there is a dearth of research focused on modeling the relationship between meteorological factors and the COVID-19 pandemic, so this work seeks to remedy this situation and provide useful insights for researchers and public health decision-makers.

This research therefore investigates the significance of Saudi Arabia's arid climate on the transmission of COVID19 based on statistical analysis. In addition, we propose a count regression models that allows us to describe the links that may exist between climate variables and COVID-19 daily-confirmed cases in Saudi Arabia.

\section{Methods}

Data collected for COVID-19 infection cases took the form of count data with only non-negative integers. Counts are discrete data, so they therefore need to be treated as such (see O'Hara and Kotze 2010). Negative binomial regression (Cox and Snell 1989) and Poisson regression (Griffith and Haining 2006; Colin 2013) are common tools for analyzing count data. 
A more promising way to account for overdispersion is to use a negative binomial regression model, this time using a new form of distribution. Negative binomial regression comes in many forms, but one of these is particularly attractive since it comes from the exponential family and is therefore part of the GLMs (see Hilbe 2014).

Poisson regression (PR) therefore appears to be the model best suited to data for new COVID-19 cases. It can be defined as follows:

$p=\left[Y_{t}=y_{t}\right]=\frac{\mathrm{e}^{-\lambda} \lambda^{y_{t}}}{y_{t} !}$

where $P($.$) is the probability of Y$ infected people being observed on day $t$. For the Poisson distribution, $Y_{t}$ takes integer values, while $\lambda$ denotes the average event occurrence (i.e., the anticipated number of COVID-19 infections) on date $t$. According to the Poisson regression model, the expected number of COVID-19 infections is determined by the vector of explanatory variables $X_{t}$, such that:

$\lambda_{t}=\exp \left(X_{t}^{\prime} \beta\right)$

where $\beta$ is the vector of estimated coefficients for the exploratory variables. The explanatory variables are divided into two categories, quantitative variables, such as differences in temperature and wind speed, and binary variables that take the value of one if an event occurs, such as the suspension of domestic flights, the suspension of international flights, and the imposition of a curfew.

The model is estimated using the max likelihood method as follows:

$\operatorname{lnL}(\beta)=\sum_{t} \exp \left(X_{t}^{\prime} \beta\right)+\left(X_{t}^{\prime} \beta\right) y_{t}-\ln y_{t} !$

The Poisson distribution is characterized by equidispersion, which is rarely achieved in statistical data, with "overdispersion" being more likely to prevail in the data. Thus, we apply negative binomial regression (NBR) to relax the Poisson assumption that the mean equals the variance.

This overdispersion follows the heterogeneity of observations (i.e., the number of new COVID-19 infection cases). The NBR model makes it possible to fill this overdispersion gap by attributing the Gamma distribution to the error term and adding an additional random component.

The specification for model 2 therefore becomes:

$\lambda_{t}=\exp \left(X_{t}^{\prime} \beta+\varepsilon_{t}\right)$

where $\varepsilon_{\tau} \sim \operatorname{Gamma}(1, \alpha)$, with mean 1 and variance $\alpha$, which is the overdispersion parameter. We use Pearson chi-square statistics to detect the overdispersion of the variance, such that when $\alpha>0$, overdispersion occurs.
We also introduce unobserved effects into the conditional mean of the Poisson model to obtain:

$\ln \left(\lambda_{t}\right)=X_{t}^{\prime} \beta+\varepsilon_{t}$

\section{Results}

The daily data that were analyzed comprised new cases of COVID-19 in three major cities of Saudi Arabia (Riyadh, Jeddah, and Makkah), and these were gathered from the Saudi Ministry of Health for the period from March 9, 2020 to November 19, 2020. The meteorological and air pollution data, meanwhile, were sourced from the General Authority of Meteorology and Environmental Protection (GAMEP) and the Saudi National Oceanic and Atmospheric Administration (SNOAA). The basic meteorological parameters used in this study were the difference in temperature (Diff_Temp) and wind speed (Wind_speed).

Table 1 shows the distribution of identified COVID-19 cases during the study period in the three major cities. These cases represent $39.76 \%$ of all confirmed cases in Saudi Arabia and $56 \%$ of all COVID-19 deaths, despite these cities only hosting $31 \%$ of the total population of Saudi Arabia. The high population density in these cities, in association with meteorological factors, is presumed to promote the spread of COVID-19 and increase the number of subsequent deaths.

Table 2 provides some descriptive statistics, such as the mean, standard error, minimum, and maximum of the two meteorological parameters, three daily mean concentrations of pollutants, and the two measures relating to COVID-19 cases and deaths. As we can see, the differences between the median and maximum values for the number of COVID-19 cases and deaths for all the cities are relatively high, indicating extreme values at the peak of the pandemic in the summer of 2020. Similarly, we can see significant differences in the median and maximum values for temperature and wind speed. This is because there may be times during the day when the minimum temperature drops very low or increases very highly (i.e., a high thermal amplitude). To consider this aspect, we

Table 1 Repartition of COVID-19 cumulative cases and mortalities

\begin{tabular}{|c|c|c|c|c|c|c|}
\hline \multirow[b]{2}{*}{ Series } & \multicolumn{2}{|c|}{ Population* } & \multicolumn{2}{|c|}{ Cumulative cases } & \multicolumn{2}{|c|}{ Mortalities } \\
\hline & In level & $\%$ & In level & $\%$ & In level & $\%$ \\
\hline Riyadh & 5236901 & 15.67 & 72535 & 20.44 & 1226 & 21.34 \\
\hline Jeddah & 3457794 & 10.35 & 34097 & 9.61 & 1107 & 19.27 \\
\hline Makkah & 1684480 & 5.04 & 34470 & 9.71 & 862 & 15.00 \\
\hline Saudi Arabia & 33413660 & 100 & 354813 & 100 & 5745 & 100 \\
\hline
\end{tabular}

*The General Authority for statistics, Saudi Arabia 
Table 2 Descriptive statistics

\begin{tabular}{|c|c|c|c|c|c|c|}
\hline Series & Obs & Mean & Std Error & Minimum & Maximum & Median \\
\hline \multicolumn{7}{|l|}{ Riyadh } \\
\hline Cases & 256 & 233.089 & 348.279 & 0 & 2371 & 101 \\
\hline Mortalities & 256 & 4.777 & 6.950 & 0 & 36 & 2 \\
\hline Wind_speed & 256 & 2.823 & 1.141 & 1.6 & 6.57 & 2.8 \\
\hline Diff_Temp & 256 & 14.444 & 2.553 & 4 & 20 & 11 \\
\hline $\mathrm{PM}_{10}$ & 256 & 351 & 14.98 & 310 & 418 & 364 \\
\hline $\mathrm{NO}_{2}$ & 256 & 38.5 & 10.55 & 23.4 & 53.1 & 40.3 \\
\hline $\mathrm{O}_{3}$ & 256 & 42.4 & 8.41 & 28.36 & 58.6 & 46.7 \\
\hline \multicolumn{7}{|l|}{ Jeddah } \\
\hline Cases & 256 & 133.19 & 146.181 & 0 & 586 & 56.5 \\
\hline Mortalities & 256 & 4.324 & 3.905 & 0 & 21 & 3 \\
\hline Wind_speed & 256 & 5.368 & 2.119 & 2.1 & 21.6 & 7.2 \\
\hline Diff_Temp & 256 & 9.566 & 2.451 & 3.4 & 19.4 & 7 \\
\hline $\mathrm{PM}_{10}$ & 256 & 128 & 25.3 & 98.5 & 173.6 & 123.8 \\
\hline $\mathrm{NO}_{2}$ & 256 & 33.7 & 3.28 & 27.4 & 42.3 & 31.6 \\
\hline $\mathrm{O}_{3}$ & 256 & 52.12 & 4.31 & 43.61 & 63.47 & 53.8 \\
\hline \multicolumn{7}{|l|}{ Makkah } \\
\hline Cases & 256 & 134.65 & 132.676 & 0 & 623 & 75.5 \\
\hline Mortalities & 256 & 3.367 & 2.939 & 0 & 14 & 3 \\
\hline Wind_speed & 256 & 2.790 & 1.038 & 1.3 & 4.7 & 3.5 \\
\hline Diff_Temp & 256 & 11.11 & 2.451 & 3.2 & 17.8 & 8.1 \\
\hline $\mathrm{PM}_{10}$ & 256 & 156.8 & 8.38 & 142.5 & 169.3 & 157.2 \\
\hline $\mathrm{NO}_{2}$ & 256 & 16.46 & 2.32 & 12.7 & 20.15 & 15.89 \\
\hline $\mathrm{O}_{3}$ & 256 & 42.8 & 7.6 & 34.21 & 51.62 & 41.3 \\
\hline
\end{tabular}

used the temperature difference variable. Concerning the $\mathrm{PM}_{10}$ pollutant, the World Health Organization (WHO) recommends an average daily threshold of $50 \mu \mathrm{g} / \mathrm{m} 3$, which is greatly exceeded by the cities of Saudi Arabia. For other pollutants $\left(\mathrm{NO}_{2}\right.$ and $\left.\mathrm{O}_{3}\right)$, the health standards of the WHO are respected.

Table 3 proves that the three cities present a significant correlation between daily cases of COVID-19 and the pollutant particles. Air pollution levels for the three pollutants $\left(\mathrm{PM}_{10}, \mathrm{NO}_{2}, \mathrm{O}_{3}\right)$ are all positively correlated to daily cases of COVID-19. This table clearly reveals significant links between the daily number of COVID-19 infections and meteorological parameters.
Tables 4, 5, and 6 present maximum likelihood estimates for the Poisson and binomial negative models' parameters for the cities of Makkah, Jeddah, and Riyadh. The estimation results indicate a strong relationship between the number of COVID-19 cases and the meteorological parameters for Riyadh and Makkah due to the high population density in these cities. For both models, the statistical significance of the coefficients ( $p$ value) indicates that variations in temperature difference and wind speed influence the number of COVID-19 cases. However, for the city of Jeddah, the estimates obtained show that the temperature difference variable is positively but not significantly related to COVID-19 cases, while the wind speed variable is significantly related at the $5 \%$
Table 3 Results of Pearson correlation test

\begin{tabular}{llllll}
\hline Variables & \multicolumn{2}{l}{ New cases for the three cities } \\
\cline { 2 - 5 } Pearson correlation coefficient & Wind_speed & Diff_Temp & $\mathrm{PM}_{10}$ & $\mathrm{NO}_{2}$ & $\mathrm{O}_{3}$ \\
\hline Riyadh & $-0.04^{* * *}$ & $0.46^{* *}$ & $0.68^{* * *}$ & $0.48^{* *}$ & $0.46^{* *}$ \\
Jeddah & -0.02 & 0.42 & $0.54^{* * *}$ & $0.37^{*}$ & $0.35^{* *}$ \\
Makkah & $-0.07^{* * *}$ & $0.38^{* *}$ & $0.36^{* *}$ & $0.31^{*}$ & $0.29^{*}$ \\
\hline
\end{tabular}

$* * *$ stands for $1 \%$ level of significance. $* *$ stands for $5 \%$ level of significance. * stands for $10 \%$ level of significance 
level in the case of the Poisson regression model but not significantly related with the negative binomial model.

Concerning the effect of pollutants on the spread of the virus, we observe significantly positive associations with short-term exposure to high concentrations of $\mathrm{PM}_{10}, \mathrm{NO}_{2}$, and $\mathrm{O}_{3}$ with confirmed cases of COVID-19. These results confirm the descriptive statistics and correlation tests above. They confirm that under certain conditions of high concentrations of PM10 associated with atmospheric stability (during the summer of 2020), SARS-CoV-2 gives rise to clusters with external PM10 and contributes to the persistence of the virus in the atmosphere.

In the same way, Wu et al. (2020) have shown that air pollution negatively affects early immune responses to COVID-19 infection in the USA. Other studies, mainly in northern Italy, have shown the importance of air pollution in the spread and worsening of the epidemic (Setti et al. 2020; Conticini et al. 2020). These studies focused on one of the most polluted regions in Europe with high levels of PM and a particular climate such as Lombardy and the Po Valley.

In addition, the coefficients associated with the domestic flight variable are negative and significant for the three cities at the $1 \%$ level for both models. In addition, the coefficients associated with the two variables for international flights and curfew restrictions are positive and significant for the three cities at the $1 \%$ level.

Riyadh has a high level of temperature difference with an IRR of 2.054 , so it is more likely to experience a greater number of COVID-19 cases than the other two cities. The effect of the wind speed variable is almost the same for the three cities, with an IRR close to 1 .

We used goodness-of-fit statistics-namely, pseudo- $R^{2}$, $\log$ likelihood, and Akaike information criteria (AIC) - to assess the relevance of the statistical specifications obtained through Poisson and negative binomial regression. According to the AIC and log-likelihood values, the best model out of the two is the negative binomial model with a logarithmic link function.

\section{Discussion}

The meteorological parameters, namely, temperature difference and wind speed, can increase or decrease the spread of the virus. It is therefore necessary to understand the relationship between virus transmission and climatic conditions.

In the present work, the association between COVID-19 cases and weather conditions was analyzed. The count regression models made it possible to highlight the role that meteorological parameters (i.e., temperature difference and wind speed) played in the evolution of the COVID-19 pandemic.

Based on the analysis of the count data models, the differences in temperature positively and significantly affect the number of COVID-19 cases. The increased temperature in summer likely had the effect of encouraging people to spend more time inside in enclosed areas that were poorly ventilated and heavily air-conditioned. This behavior is reflected in increased cases in the three cities. This reminds us that seasonal factors can play a role even in warm climates; similar to how colder weather in European climates drives people inside more. What is more, the wind speed variable was found to have a significant negative influence on daily COVID-19 cases. It seems a stronger wind helps clean the air of the virus and thus reduces transmission of COVID-19 in the three cities.

Heavy exposure to PM10 in major Saudi cities has had a "boost effect" in the spread of the virus. Air pollution is therefore one of the lethal factors for SARS-CoV-2. Indeed, the spread of the epidemic in Saudi Arabia was strongest in cities with a high population concentration and high level of atmospheric pollutant.

Multiple studies have highlighted the effect of proinflammatory particles in suspension in the respiratory system, resulting in a weakening of the immune system (Harmon et al. 2018). Several hypotheses can therefore be formulated with regard to the SARS-CoV-2 virus:

1. Air pollution weakens the respiratory system, leading to more-severe infection. A study of 324 cities in China (Tian et al. 2020) found that an increase of $10 \mu \mathrm{g} / \mathrm{m} 3$ of $\mathrm{NO} 2$ led to a $22 \%$ [7\%-40\%] increase in COVID-19 cases, while the same increase in PM2.5 led to a $15 \%$ [6\%-26\%] increase in COVID-19 cases. Other studies in the Netherland context confirm these results (Andree 2020; Cole et al. 2020). Thus, air pollution is likely to increase cases of infection with SARS-CoV-2 due to its deleterious effect on the lungs

2. Suspended particles play a role in transmitting infectious diseases, such as avian flu and SARS. A virus can remain viable in aerosols for several hours, and its ability to infect people remains high. Van Doremalen et al. (2020) compared the viability of the SARS-CoV-2 virus, which causes COVID-19, and SARS-CoV-1 virus, which causes SARS, and found that COVID-19 is transmitted through aerosols, because the virus can remain viable in aerosols for hours and on surfaces for days, depending on how much virus is being spread

3. Certain weather conditions, such as a stark temperature difference, may affect the respiratory tracts of people and promote infection by SARS-CoV-2

4. Airborne transmission cannot be ruled out, especially in an enclosed environment. For example, people who rely on air conditioning in hot regions, as is the case in Saudi Arabia, may be more vulnerable to infection in closed environments (Morawska and Cao 2020). Indeed, outbreaks have been mainly identified in enclosed locations, such as restaurants, cruise ships, public transport, and 
prayer rooms, as well as family homes. Ventilation and air flow are therefore desirable to prevent COVID-19 infections, and lower temperatures will reduce the need for enclosed air conditioning.

The imposition of a curfew in the three major cities on March 15, 2020, did not have the expected results, and it did not reduce the progression of the pandemic, with the curfew variable instead having a positive and significant effect on the number of COVID-19 cases.

\section{Conclusion}

In summary, our study demonstrated that meteorological parameters and exposition to air pollution play a role in the human-to-human transmission of COVID-19 through close contact in the family environment and enclosed areas characterized by poor ventilation and air conditioning. According to some studies, the warm, arid climate of Saudi Arabia increases the risk of contracting a respiratory disease. Our results support those of a study carried out in China for the regions of Hong Kong, Guangzhou, Beijing, and Taiyuan, which indicated a significant surge in SARS cases related to temperature variations (Tan and Lim 2005). What is more, the World Health Organization has indicated that the virus is spread mainly through the respiratory exhalations of infected people, so poor ventilation and air-conditioning systems in indoor environments can play a significant role in increasing the spread of COVID-19.

Our results advocates for the importance of pollutant levels in the atmosphere in the spread of the SARS-CoV-2 virus. Despite the existence of significant evidence on the importance of pollutant in the transmission of the SARS-CoV-2 virus, little evidence is substantiated in the scientific work. Our results also indicate a negative effect of wind speed on the transmission of COVID-19. This suggests that in addition to the direct human-to-human transmission of COVID-19, high concentrations of atmospheric pollutants that are associated with low wind speeds may allow viral particles to persist for longer in the air of the studied cities, thus, providing an indirect means of transmission. This finding is supported by Coccia (2020), who concluded that Italian cities that were characterized by higher wind speeds had a lower number of COVID-19 cases. Cities with lower wind speeds, often with high levels of air pollution, suffered from greater COVID-19 infections.

The consensus of the results of studies in several regions of the world points to one of the causality factors, but this alone is not sufficient. The consideration of air pollution in measures to combat the pandemic is also arguably needed.

This study contributes to the extension of research in this field and allows laying the foundations for other future work on the contribution of air pollution in the spread of the SARS$\mathrm{CoV}-2$ virus. In addition, the population clearly needs to remain in strict compliance with preventive measures, however, because everyone's health depends on this, as well as the possibility of getting our lives back to a level of normality.

\section{Appendix}

Table 4 Estimation results for Makkah coronavirus cases

\begin{tabular}{|c|c|c|c|c|}
\hline & \multicolumn{2}{|l|}{ Poisson model } & \multicolumn{2}{|c|}{ Negative binomial model } \\
\hline & Estimate & IRR & Estimate & IRR \\
\hline Intercept & $3.939 * * *(0.000)$ & 51.367 & $3.518 * * *(0.000)$ & 33.717 \\
\hline $\begin{array}{l}\text { Xwind_speed_ } \\
\text { rate }\end{array}$ & $-0.031 * * *(0.000)$ & 0.968 & $-0.042 * *(0.012)$ & 0.957 \\
\hline XDiff_Temp & $0.031 * * *(0.000)$ & 0.969 & $0.04 *(0.078)$ & 1.004 \\
\hline $\mathrm{PM}_{10}$ & $0.12 * * *(0.000)$ & 1.127 & $0.09 * *(0.04)$ & 1.094 \\
\hline $\mathrm{NO}_{2}$ & $0.03(0.12)$ & 1.031 & $0.01(0.14)$ & 1.010 \\
\hline $\mathrm{O}_{3}$ & $0.07(0.15)$ & 1.073 & $0.05(0.11)$ & 1.051 \\
\hline Xflights dom & $-0.479 * * *(0.000)$ & 0.619 & $-0.525(0.022)$ & 0.591 \\
\hline Xflights int & $1.102 * * *(0.000)$ & 3.010 & $1.121 * * *(0.000)$ & 3.068 \\
\hline Xcurfew_lock & $1.188^{* * * *}(0.000)$ & 3.282 & $1.295 * * *(0.000)$ & 3.652 \\
\hline Log. Lik ${ }^{-}$ & -12641.67 & - & -1326.78 & - \\
\hline Pseudo- $R^{2}$ & 0.51 & - & 0.82 & - \\
\hline AIC & 28217 & - & 3054.2 & - \\
\hline Residual deviance & 1439 & - & $294.65 * * *(0.000)$ & - \\
\hline
\end{tabular}

Signif. codes: 0 “***” 0.001 “*** 0.01 “*” 0.05 “.” 0.1 “” 1

Table 5 Estimation results for Jeddah coronavirus cases

\begin{tabular}{|c|c|c|c|c|}
\hline & \multicolumn{2}{|l|}{ Poisson model } & \multicolumn{2}{|c|}{ Negative binomial model } \\
\hline & Estimate & IRR & Estimate & IRR \\
\hline Intercept & $3.003 * * *(0.000)$ & 20.47 & $3.013 * * *(0.000)$ & 20.348 \\
\hline Xwind_speed_rate & $-0.005^{*}(0.016)$ & 1.006 & $-0.003 *(0.081)$ & 1.003 \\
\hline XDiff_Temp & $0.003(0.170)$ & 1.003 & $0.004(0.867)$ & 1.004 \\
\hline $\mathrm{PM}_{10}^{-}$ & $0.19 * * *(0.000)$ & 1.209 & $0.16^{* * *}(0.000)$ & 1.174 \\
\hline $\mathrm{NO}_{2}$ & $0.04 * *(0.000)$ & 1.041 & $0.04 * * *(0.000)$ & 1.041 \\
\hline $\mathrm{O}_{3}$ & $0.07 * * *(0.004)$ & 1.073 & $0.06 * * *(0.00)$ & 1.062 \\
\hline Xflights dom & $-0.598 * * *(0.000)$ & 0.549 & $-0.870 * * *(0.000)$ & 0.418 \\
\hline Xflights_int & 1.530 *** $(0.000)$ & 4.619 & $1.511 * * *(0.000)$ & 4.533 \\
\hline Xcurfew_lock & $1.400 * * *(0.000)$ & 4.057 & $1.645 * * *(0.000)$ & 5.183 \\
\hline Log. Lik & -12365.24 & - & -1298.31 & - \\
\hline Pseudo- $\mathrm{R}^{2}$ & 0.51 & - & 0.79 & - \\
\hline AIC & 28217 & - & 2805.7 & - \\
\hline Residual deviance & 1557 & - & $291.16 * * *(0.000)$ & - \\
\hline
\end{tabular}

Signif. codes: 0 “***» 0.001 “***” 0.01 “*” 0.05 “.” 0.1 “” 1 
Table 6 Estimation results for Riyadh coronavirus cases

\begin{tabular}{|c|c|c|c|c|}
\hline & \multicolumn{2}{|l|}{ Poisson model } & \multicolumn{2}{|c|}{ Negative Binomial model } \\
\hline & Estimate & IRR & Estimate & IRR \\
\hline Intercept & $3.019 * * *(0.000)$ & 20.47 & $3.182 * * *(0.000)$ & 24.09 \\
\hline Xwind speed rate & $-0.101 * * *(0.000)$ & 0.903 & $-0.053 * * *(0.000)$ & 0.947 \\
\hline XDiff_Temp & $0.372 * * *(0.000)$ & 1.45 & $0.720 * * *(0.000)$ & 2.054 \\
\hline $\mathrm{PM}_{10}^{-}$ & $0.23 * * *(0.000)$ & 1.259 & $0.21 * * *(0.000)$ & 1.234 \\
\hline $\mathrm{NO}_{2}$ & $0.05 * *(0.000)$ & 1.051 & $0.04 * * *(0.000)$ & 1.041 \\
\hline $\mathrm{O}_{3}$ & $0.09 * * *(0.005)$ & 1.094 & $0.08 * * *(0.00)$ & 1.083 \\
\hline Xflights_dom & $-1.075 * * *(0.000)$ & 0.341 & $-1.146^{* * *}(0.000)$ & 0.317 \\
\hline Xflights_int & $1.152 * * *(0.000)$ & 3.165 & $1.086 * * *(0.000)$ & 2.963 \\
\hline Xcurfew_lock & $1.960 * * *(0.000)$ & 7.105 & $1.966 * * *(0.000)$ & 7.145 \\
\hline Overdispersion test & $10.609 * * *(0.000)$ & - & - & - \\
\hline Log. Lik & -12421.23 & - & -1353.45 & - \\
\hline Pseudo- $\mathrm{R}^{2}$ & 0.46 & - & 0.81 & - \\
\hline $\mathrm{AIC}$ & 28217 & - & 3054.2 & - \\
\hline Residual deviance & 2655 & - & $287.50 * * *(0.000)$ & - \\
\hline
\end{tabular}

Signif. codes: 0 “***” 0.001 “**” 0.01 “*” 0.05 “.” 0.1 “" 1

Acknowledgments The authors extend their appreciation to the Deanship of Scientific Research at University of Bisha Saudi Arabia for funding this work through COVID-19 Initiative Project under Grant Number (UB - COVID - 35-1441)

Author's contribution Abderrazek Ben Maatoug: supervision, conceptualization, methodology, data curation, writing-original draft preparation, and editing. Mohamed Bilel Triki: conceptualization, methodology, visualization, investigation, data curation, writing-original draft preparation, validation. Hesham Fazel: investigation.

Availability of data and materials Extra data is available by emailing to mtriki@ub.edu.sa on reasonable request.

\section{Declarations}

Ethics approval and consent to participate "Not applicable."

Consent for publication "Not applicable."

Competing of interests The authors declare no competing interests.

\section{References}

Andree BPJ. 2020. Incidence of COVID-19 and connections with air pollution exposure: evidence from the Netherlands. World Bank Policy Research Working Paper.

Brandt EB, Beck AF, Mersha TB (2020) Air pollution, racial disparities, and COVID-19 mortality. J Allergy Clin Immunol 146:61e63

Brassey J, Mahtani KR, Jeffrey KA (2020) Do weather conditions influence the transmission of the coronavirus (SARS-CoV-2)? 2020; Retrieved from https://www.cebm.net/covid-19/do-weather-conditions-influencethe-transmission-of-the-coronavirus-sars-cov-2/

Bull G (1980) The weather and deaths from pneumonia. Lancet 315: 1405-1408

Cameron A. Colin. (2013). Regression analysis of count data. Cambridge University Press; 2nd edition
Chan S, Chu J, Zhang Y, Nadarajah S (2021) Count regression models for COVID-19. Physica A 563:125460. https://doi.org/10.1016/j.physa. 2020.125460

Chen Y, Liu Q, Guo D (2020) Emerging coronaviruses: genome structure, replication, and pathogenesis. J Med Virol 92:418-423. https:// doi.org/10.1002/jmv.25681

Coccia M (2020) Factors determining the diffusion of COVID-19 and suggested strategy to prevent future accelerated viral infectivity similar to COVID. Sci Total Environ 729:138474

Cole MA, Ozgen C, Strobl E. 2020. Air pollution exposure and COVID19. IZA - Institute of Labor Economics; DISCUSSION PAPER SERIES, No. 13367.

Conticini E, Frediani B, Caro D (2020) Can atmospheric pollution be considered a co-factor in extremely high level of SARS-CoV-2 lethality in Northern Italy? Environ Pollut 261:114465

Cox DR \& Snell EJ (1989). Analysis of binary data. 2nd Edition. Chapman and Hall New York.

Dalziel P, Saunders C, Saunders J (2018) Wellbeing economics: the capabilities approach to prosperity. Palgrave Macmillan, London

Dutheil F, Baker JS, Navel V (2020) COVID-19 as a factor influencing air pollution? Environ Pollut 263:114466

Griffith DA, Haining R (2006) Beyond mule kicks: the Poisson distribution in geographical analysis. Geogr Anal 38:123-139

Gupta S, Raghuwanshi GS, Chanda A. 2020. Effect of weather on COVID-19 spread in the US: a prediction model for India in 2020. In: Science of the total environment, $p 138860$

Harmon AC, Hebert VY, Cormier SA, Subramanian B, Reed JR, Backes WL, Dugas TR (2018) Particulate matter containing environmentally persistent free radicals induces AhR-dependent cytokine and reactive oxygen species production in human bronchial epithelial cells. PLoS One 13:e0205412

Hilbe, J. M. 2014. Modeling count data. Cambridge University Press; 1nd edition

Kumar G, Kumar RR (2020) A correlation study between meteorological parameters and COVID-19 pandemic in Mumbai, India. Diabetes Metab Syndr Clin Res Rev 14(6):1735-1742

Ma Y, Zhao Y, Liu J, He X, Wang B, Fu S, Yan J, Niu J, Zhou J, Luo B (2020) Effects of temperature variation and humidity on the death of COVID-19 in Wuhan, China. In: Science of the total environment, $p$ 138226

Morawska L, Cao J (2020) Airborne transmission of SARS-CoV-2: the world should face the reality. Environ Int 139:105730

O'Hara R. B. \& Kotze D. J. 2010. Do not log-transform count data. Methods Ecol Evol, vol. 1, 2, p. 118-122.

Oztig LI, Askin OE 2020 Human mobility and coronavirus disease 2019 (COVID-19): a negative binomial regression analysis. Public Health $185: 364 \mathrm{e} 367$

Poole L, (2020). Seasonal influences on the spread of SARS-CoV-2 (COVID19), causality, and forecastabililty (3-15-2020). Causality, and Forecastabililty 3-15-2020 (March 15, 2020).

Sajadi MM, Habibzadeh P, Vintzileos A, Shokouhi S, Miralles-Wilhelm F,Amoroso A, 2020. Temperature and latitude analysis to predict potential spread and seasonality for COVID-19 (Available at SSRN 3550308).

Setti L, Passarini F, De Gennaro G, Baribieri P, Perrone MG, Borelli M, Palmisani J, Di Gilio A, Torboli V, Pallavicini A, Ruscio M, Piscitelli P, Miani A (2020) SARS-Cov-2 RNA found on particulate matter of bergamo in northern Italy: first preliminary evidence. Environ Res 188: 109754. https://doi.org/10.1016/j.envres.2020.109754

Strak M, Janssen N, Beelen R, Schmitz O, Vaartjes I, Karssenberg D, van den Brink C, Bots ML, Dijst M, Brunekreef B, Hoek G (2017) Long-term exposure to particulate matter, $\mathrm{NO}(2)$ and the oxidative potential of particulates and diabetes prevalence in a large national health survey. Environ Int 108:228e236

Tan Y-J, Lim SG (2005) Hong Characterization of viral proteins encoded by the SARS-coronavirus genome. Antivir Res 65:69-78 
To T, Zhang K, Maguire B, Terebessy E, Fong I, Parikh S, Zhu S (2020) Correlation of ambient temperature and COVID-19 incidence in Canada. Sci Total Environ 750:141484

Tian H, Liu Y, Song H, Wu C-H, Li B, Kraemer MUG, Tian H, Yan X, Zheng Y, Stenseth NC, Dye C, Jia G. 2020. Risk of COVID-19 is associated with long-term exposure to air pollution. medRxiv.

Tosepu R, Gunawan J, Effendy DS, Ahmad LOAI, Lestari H, Bahar H (2020) Correlation between weather and Covid-19 pandemic in Jakarta, Indonesia. Sci Total Environ 725:138436. https://doi.org/ 10.1016/J.scitotenv.2020.138436

Van Doremalen N, Bushmaker T, Morris DH, Holbrook MG, Gamble A, Williamson BN et al (2020) Aerosol and surface stability of SARSCoV-2 as compared with SARS-CoV-1. N Engl J Med 382:1564 1567
Wang T, Lu K, Kam Chow P, Zhu Q (2020) Covid-19 sensing: negative sentiment analysis on social media in China via bert model. IEEE Access 8:138162-138169

Wu X, Nethery RC, Sabath MB, Braun D, Dominici F (2020) Air pollution and COVID-19 mortality in the United States: strengths and limitations of an ecological regression analysis. Sci Adv 6(45): eabd4049. https://doi.org/10.1126/sciadv.abd4049

Yuan Z, Bi J, Mariguichi Y (2006) The circular economy: a new development strategy in China J. Ind Ecol 10:4-8

Publisher's note Springer Nature remains neutral with regard to jurisdictional claims in published maps and institutional affiliations. 